\title{
Calcium in Vascular Smooth Muscle Cell Elasticity and Adhesion: Novel Insights Into the Mechanism of Action
}

\begin{abstract}
Yi Zhu ${ }^{1,2}$, Jing $\mathrm{Qu}^{1,3 *}$, Li He ${ }^{1}$, Feng Zhang ${ }^{1,4}$, Zijing Zhou ${ }^{1,5}$, Shanzhong Yang ${ }^{1}$ and Yong Zhou
'Division of Pulmonary, Allergy and Critical Care Medicine, Department of Medicine, University of Alabama-Birmingham, Birmingham, AL, United States, ${ }^{2}$ Dalton Cardiovascular Research Center, University of Missouri-Columbia, Columbia, MO, United States, ${ }^{3}$ Department of Pathophysiology, School of Basic Medicine, Tongji Medical College, Huazhong University of Science and Technology, Wuhan, China, ${ }^{4}$ Department of Ophthalmology, The Second Xiangya Hospital, Central-South University, Changsha, China, ${ }^{5}$ Department of Respiratory Medicine, The Second Xiangya Hospital, Central-South University, Changsha, China
\end{abstract}

Vascular smooth muscle cells (VSMCs) are the predominant cell type in the arterial wall. These cells play a critical role in maintaining vascular homeostasis including vasoconstriction and vasodilatation through active contraction and relaxation. Dysregulation of VSMC function alters the response of blood vessels to mechanical stress, contributing to the pathogenesis of vascular diseases, particularly atherosclerosis and hypertension. The stiffness of VSMCs is a major regulator of vascular function. Previous studies suggest that intracellular $\mathrm{Ca}^{2+}$ controls the stiffness of VSMCs by a mechanism involving myosin contractile apparatus. More recent studies highlight important functions of cytoskeletal $\alpha$-smooth muscle actin ( $\alpha$-SMA), $\alpha 5 \beta 1$ integrin, and integrin-mediated cell-extracellular matrix (ECM) interactions in $\mathrm{Ca}^{2+}$-dependent regulation of VSMC stiffness and adhesion to the ECM, providing novel insights into the mechanism of calcium action.

Keywords: vascular smooth muscle cell, calcium, elasticity, adhesion, extracellular matrix-integrin-cytoskeletal axis

\section{INTRODUCTION}

Vascular smooth muscle cells (VSMCs) are mainly composed of the medial layer of the blood vessels, which are subjected to mechanical stress and pressure of blood flow, and maintain vascular tone and resistance. VSMCs not only have normal cellular functions, maintain their intrinsic properties, support vascular geometry, but also require some important actions to participate in the regulation of the biomechanical and biochemical properties of blood vessels (Li et al., 2018; Sanyour et al., 2018). In addition, VSMC alters vascular volume and local blood pressure and continuously regulates the physical and geometric shape of the blood chamber in response to blood pressure and mechanical stimulation (Hartman et al., 2016; Leloup et al., 2019).

VSMC carries out biomechanical and biochemical functions that are associated with the transformation of vascular configurations and are characterized by mechanical and physical effects such as blood vessel contraction and relaxation. Due to the various and diverse phenotypes of smooth muscle cells, these diversity effectively allow the blood vessels to gain flexibility and defend various physiological and pathological conditions (Yang et al., 2017; Hays et al., 2018).

VSMCs regulate the development and progression of vascular lesions, and the deep understanding of the relationship between vascular disease and mechanical stress provides some valuable data for the mechanical properties (e.g., elastic modulus, hardness) in those pathological processes. Currently, many publications contribute valuable data on the elastic changes of VSMC during 
physiology and disease processes and address some of the new concepts of cell elasticity in vascular disease (Sehgel et al., 2013; Sanyour et al., 2018, 2019). VSMCs are attached to the extracellular matrix (ECM) by interaction between some proteins (e.g., fibronectin, collagen) in the extracellular space and cell adhesion molecules (e.g., a5 $\beta 1$ integrin) that act as transmembrane proteins (Sehgel et al., 2015a,b; Zhang et al., 2016). The a5 $\beta 1$ integrin provides a mechanical link between the cytoskeleton (actin filament) component and the ECM, and actin responds to mechanical forces to the alternate cytoskeletal system of VSMC via integrin-mediated cell-ECM interaction (Zhou et al., 2017a,b). There is now ample evidence that the interactions between actin and integrin are responsible for reflecting and regulating the elasticity and adhesion characteristics of VSMC (Hong et al., 2015; Lacolley et al., 2017).

Calcium is a stimulator of many cellular functions, and under physiological conditions, intracellular calcium are present in VSMC to regulate many different biophysical and biochemical processes (Huang et al., 2018). The purpose of this review is to investigate the role of intracellular calcium in the regulation of VSMC elasticity and adhesion properties by influencing the ECM-integrin-cytoskeleton axis. This work summarizes a new concept that the increase in arterial stiffness is attributable to the dynamic changes of VSMC stiffness and adhesion process, opening up a new treatment for VSMC stiffness treatment of arteriosclerosis, and develops in-depth knowledge and insight into the dynamic behavior of calcium activity underlying cell hardness as well as the ability to correlate these mechanical events with ECM and cell adhesion interactions.

\section{VASCULAR SMOOTH MUSCLE CELL STIFFNESS AND ADHESION}

VSMC has a crucial function of maintaining vascular tone and resistance and involves all physiological and pathological changes that occur in the vessel wall. VSMCs are stromal cells of the blood vessel wall that are constantly exposed to mechanical signals and biochemical components produced in the blood compartment (Wang et al., 2015). The mechanical function of VSMCs relies on anchoring, requiring physical binding of cells to ECM and adjacent cells to perform force transfer functions associated with modulating vascular diameter (Zhu et al., 2018b).

Abbreviations: ANG II, Angiotensin II; $\alpha$-SMA, $\alpha$-Smooth muscle actin; BAPTA-AM, 1,2-Bis(2-aminophenoxy)ethane- $\mathrm{N}, \mathrm{N}, \mathrm{N}^{\prime}, \mathrm{N}^{\prime}$-tetraacetic acid tetrakis (acetoxymethyl ester); $\left[\mathrm{Ca}^{2+}\right]_{\mathrm{i}}$, Intercellular $\mathrm{Ca}^{2+}$ concentration; CaM, Calmodulin; CaMKII, CaM-dependent protein kinase II; CD, Cytochalasin D; COL-I, Collagen I; DAG, Diacylglycerol; ECM, Extracellular matrix; FAK, Focal adhesion kinase; FN, Fibronectin; GDP, Guanosine diphosphate; GTP, Guanosine triphosphate; GPCR, G-protein-coupled receptor; $G_{q}$, Guanine nucleotide-binding protein; $G_{a}$, $G$ Protein a subunit; $I_{3}$, Inositol trisphosphate; LM, Laminin I; LPA, Lysophosphatidic acid; LTCC, L-type $\mathrm{Ca}^{2+}$ channel; MLC, Myosin light chain; MLCK, Myosin light chain kinase; ML7, Hexahydro-1-[(5-iodo-1-naphthalenyl)sulfonyl]-1 $H$-1,4-diazepine; $\mathrm{PIP}_{2}$, Phosphatidylinositol 4,5-bisphosphate; PLC, Phospholipase C; PKC, Protein kinase C; pMLC, Myosin light chain phosphatase; pMLCK, Phosphorylated myosin light chain kinase; SHR, Spontaneously hypertensive rat; SR, Sarcoplasmic reticulum; VN, Vitronectin; VSMC, Vascular smooth muscle cell; Y27632, (1R,4r)-4((R)-1-aminoethyl)-N-(pyridin-4-yl)cyclohexanecarboxamide.
VSMC elasticity not only examines the biomechanical properties of whole cells, but also the biomechanical properties of subcellular structures such as microtubules, actin filaments, and intermediate filaments (Lacolley et al., 2018). The current study of VSMC elasticity supports a new concept that changes in VSMC stiffness, and oscillation are not only due to changes in ECM, but also due to changes in cytoskeletal actin filament content and arrangement, which are intrinsic conformations of VSMC (Hill and Meininger, 2016; Zhang et al., 2016). The cytoskeletal a-smooth muscle actin ( $\alpha$-SMA) is the actin isoform that predominates within VSMCs (Ye et al., 2014). Cytochalasin D (CD) is a drug that destroys the actin cytoskeleton network, and colchicine is another drug that depolymerizes microtubules, which are used to treat VSMCs. By CD evaluation, the a-SMA was shown to be the decisive cytoskeleton of the mechanical and elastic properties of VSMC (Zhu et al., 2012). Two forms of $\alpha$-SMA appear within VSMCs. One form is a globular monomer molecule called G-actin, and the other form is a linear doublestranded filament polymer called F-actin, which is polymerized and organized by G-actin. Dynamical alternation between G-actin and F-actin constructs different high-level linkage structures in VSMC, affecting cell elasticity and cellular stress-relaxation behavior (Hong et al., 2012, 2014). Integrins are composed of two non-covalent associated $\alpha$ and $\beta$ subunits, appear as heterodimeric transmembrane receptors for ECM proteins that mediate force transmission and signal transduction. Integrinmediated adhesion of VSMCs to ECM proteins provides an important physical link between ECM and the cytoskeleton for bidirectional transmission of mechanical forces and production of biochemical cell signals through intracellular and extracellular mechanisms (Khalili and Ahmad, 2015; Tsai et al., 2018; Shen et al., 2019). The increasing arterial stiffness in arteriosclerosis, thrombosis, and age-related vascular disease was shown to enhance the expressions of $\alpha$-actin and $\alpha 5 \beta 1$ integrin in VSMCs (Qiu et al., 2010; Laurent and Boutouyrie, 2015; DuPont et al., 2019). The a-SMA responds the bio-mechanical forces via integrinmediated cell-ECM interactions to alternate cytoskeleton system of the cell. The a5 $\beta 1$ integrin works as the dominant fibronectin $(\mathrm{FN})$ receptor to provide the bio-mechanical linkage between a-SMA and FN in extracellular space (Wu et al., 2010; Dhar et al., 2017). Inflexible VSMC stiffness and inefficient interaction with a5 31 integrin cause arterial stiffness to respond slowly and toughly to mechanical stresses from the blood flow. Conversely, flexible VSMC elasticity and active interaction with $\alpha 5 \beta 1$ integrin will efficiently respond to mechanical stress from the blood flow (Brozovich et al., 2016). The abnormal interaction between a5 $\beta 1$ integrin and $\alpha$-SMA in VSMC is a main factor to cause the chaos of vascular tone and some vascular diseases such as hypertension, and VSMC is regulated by the cytosolic $\mathrm{Ca}^{2+}$ level and $\mathrm{Ca}^{2+}$ sensitivity of cytoskeletal filaments (Pierce, 2017).

\section{CALCIUM AND ECM-INTEGRIN- CYTOSKELETAL AXIS}

As one of the most popular second messengers, $\mathrm{Ca}^{2+}$ plays an important role in cell signaling and enters the cytoplasm 
through calcium channels on the membrane of VSMC (such as $\mathrm{Ca}^{2+}$ binding receptors and voltage-gated calcium channels) and some internal organelles (e.g., endoplasmic reticulum or mitochondria). In VSMCs, intracellular $\mathrm{Ca}^{2+}$ concentration $\left(\left[\mathrm{Ca}^{2+}\right]_{\mathrm{i}}\right)$ is in a range of 100 to $10,000 \mathrm{nM}$, while $\mathrm{Ca}^{2+}$ concentration in extracellular space is $2 \mathrm{mM}$ (Sun et al., 2017). Increasing $\left[\mathrm{Ca}^{2+}\right]_{\mathrm{i}}$ activates VSMC elastic and adhesive functions by way of two avenues: 1) entry of $\mathrm{Ca}^{2+}$ from extracellular space through specific ion channel, such as L-type $\mathrm{Ca}^{2+}$ channel (LTCC); 2) release of $\mathrm{Ca}^{2+}$ from intracellular organelles (sarco/ endoplasmic reticulum) (Brozovich et al., 2016; Rodenbeck et al., 2017). $\left[\mathrm{Ca}^{2+}\right]_{\mathrm{i}}$ performs a major role in the regulation of VSMC elasticity and adhesion by influencing the ECM-integrin-cytoskeletal axis (Wu et al., 1998, 2001). The a-SMA of cytoskeleton importantly responds mechanical forces through integrin-mediated cell-ECM interactions to mediate VSMC stiffness and adhesive processes, and its activity and expression are modulated by $\left[\mathrm{Ca}^{2+}\right]_{\mathrm{i}} \cdot\left[\mathrm{Ca}^{2+}\right]_{\mathrm{i}}$ regulates the $\alpha 5$ integrin subunit activity and expression, and the $\beta 1$ integrin subunit is responsible to perform $\mathrm{Ca}^{2+}$ entry. $\left[\mathrm{Ca}^{2+}\right]_{\mathrm{i}}$ is a hub for the regulation of elasticity and adhesion of VSMC by influencing the ECM-integrin cytoskeletal axis to configure contractility and cell signaling (Huang et al., 2018).
This information is important advancements in our understanding of VSMC stiffness and ECM adhesion coordination mechanisms.

\section{$\left[\mathrm{Ca}^{2+}\right]_{\mathrm{i}}$ Regulates Expression of $\alpha$-SMA in VSMCs}

The current researches reported that the expression and production of $a$-SMA in VSMCs are regulated by $\left[\mathrm{Ca}^{2+}\right]_{\mathrm{i}}$ level. Ionomycin, a drug that increases $\left[\mathrm{Ca}^{2+}\right]_{\mathrm{i}}$ levels, was used to treat VSMCs and induce the increases in VSMC elasticity and adhesion activities, whereas they decreased after drug BAPTA-AM treatment to reduce $\left[\mathrm{Ca}^{2+}\right]_{\mathrm{i}}$. Ionomycin treatment was also observed the area and height of VSMCs to be expanded and increased due to developing cytoskeletal a-SMA production and promoting F-actin assembly. In contrast, BAPTA-AM decreased the area and height of VSMCs due to reducing cytoskeletal $\alpha$-SMA production and preventing F-actin assembly (Zhu et al., 2018a) (Figure 1A, Reprinted from Zhu et al., 2018 b by published permission).

Angiotensin II (ANG II) is a peptide chain and complicatedly converted by Angiotensin I, and Angiotensin II is found in VSMCs to stimulate the Gq protein and start a series of cascade reactions increasing $\left[\mathrm{Ca}^{2+}\right]_{\mathrm{i}}$ level (Meininger et al., 1991). ANG
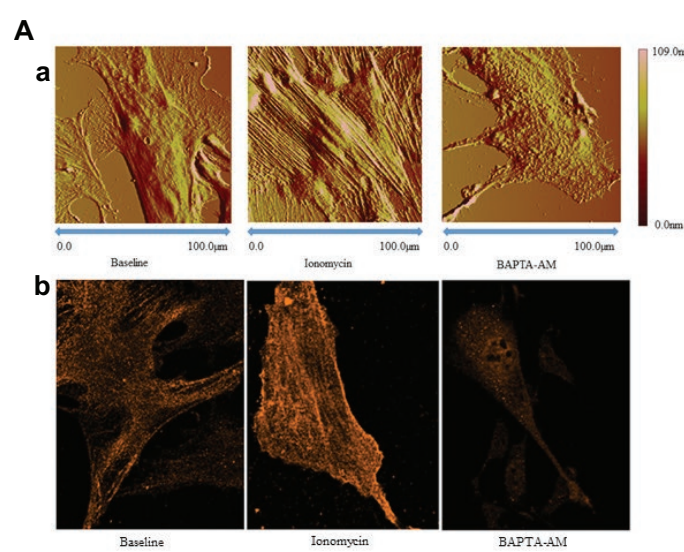

C
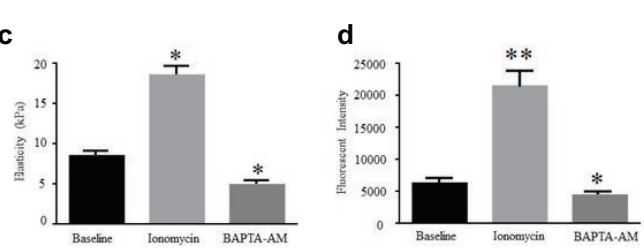

B

a
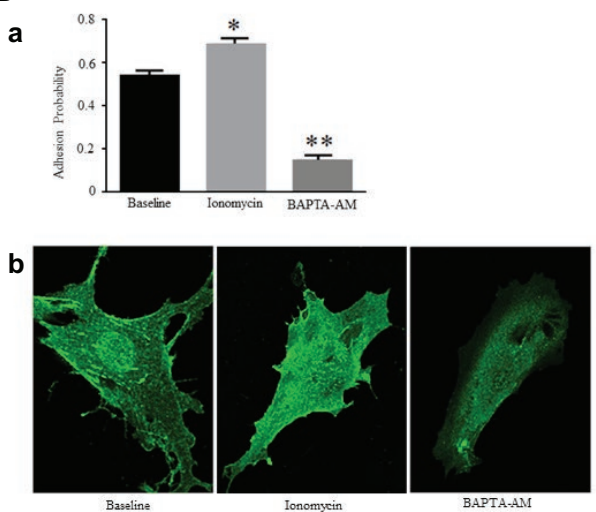

c

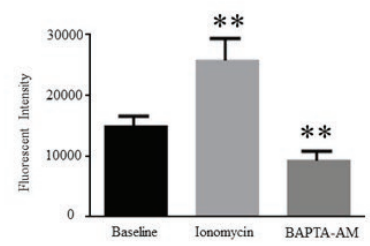

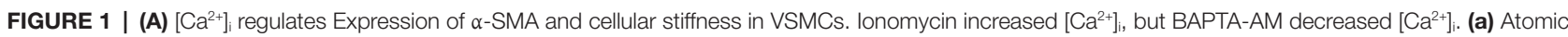
force microscopy topography analysis of VSMCs treated with or without drugs by increasing or decreasing $\left[\mathrm{Ca}^{2+}\right]$. The VSMC area and height increase by a higher $\left[\mathrm{Ca}^{2+}\right]_{i}$ level, and those decrease by a lower $\left[\mathrm{Ca}^{2+}\right]_{i}$ level. (b) Atomic force microscopy stiffness analysis of VSMCs treated with or without drugs by increasing or decreasing $\left[\mathrm{Ca}^{2+}\right]_{\text {. }}$ (c) Representative confocal immunofluorescent images showed $\alpha$-SMA expression of VSMCs treated with or without drugs by increasing or decreasing $\left[\mathrm{Ca}^{2+}\right]_{\text {. }}$ (d) $\alpha$-SMA-positive signals among VSMCs treated with or without drugs by increasing or decreasing $\left[\mathrm{Ca}^{2+}\right]_{\text {. }}$. Results are expressed as mean \pm SEM, ${ }^{\star *} p<0.01$ and ${ }^{*} p<0.05$ vs. baseline. Reprinted from Zhu et al. (2018b) by published permission. (B) [Ca $\left.{ }^{2+}\right]$ regulates $\alpha 5$ integrin subunit expression and $\alpha 5 \beta 1$ integrin adhesion activities in VSMCs. Ionomycin increased $\left[\mathrm{Ca}^{2+}\right]$, but BAPTA-AM decreased $\left[\mathrm{Ca}^{2+}\right]_{\text {: }}$ (a) Atomic force microscopy measurement of probability of adhesion to FN matrix of VSMCs treated with or without drugs by increasing or decreasing $\left[\mathrm{Ca}^{2+}\right]_{\text {: }}$ (b) Representative confocal immunofluorescent images showed $\alpha 5$ integrin expression of VSMCs treated with or without drugs by increasing or decreasing $\left[\mathrm{Ca}^{2+}\right]_{\text {: }}$ (c) $\alpha 5$ integrin-positive signals among VSMCs treated with or without drugs by increasing or decreasing $\left[\mathrm{Ca}^{2+}\right]$. Results are expressed as mean \pm SEM, ${ }^{* *} p<0.01$ and ${ }^{*} p<0.05$ vs. baseline. Reprinted from Zhu et al. (2018b) by published permission. 
II generates to increase $\left[\mathrm{Ca}^{2+}\right]_{\mathrm{i}}$ by way of $\mathrm{Gq}$ protein pathway and induce a significant elevation in VSMC density and direction of actin stress fibers for promoting the VSMC stiffness (Hong et al., 2015).

If $\left[\mathrm{Ca}^{2+}\right]_{\mathrm{i}}$ exceeds the physiological requirement within VSMCs, it also will induce some vascular dysfunctions and diseases, such as hypertension. Hypertension is a common age-related vascular disease, and many factors can induce age-related vascular dysfunctions and diseases. However, a less efficiency of intracellular $\mathrm{Ca}^{2+}$ activity to attenuate the function of ECM-integrin-cytoskeletal axis regulating VSMC elasticity importantly contributes to induce hypertension (Touyz et al., 2018). With the age increasing, the regulative ability of cytosolic $\mathrm{Ca}^{2+}$ attenuates and makes VSMC to be stiffer and more adhesive to FN matrix, and the coordinate ability of integrin-actin reacts slowly due to a low intracellular $\mathrm{Ca}^{2+}$ signal transduction activity (Ghosh et al., 2017). VSMCs of old monkeys were shown a significantly increasing in cellular area and height in comparison to those of young counterparts. The VSMC area and height of spontaneously hypertensive rats (SHR) were also found a significant elevation in comparison to those of wild-type rats. The VSMC topography and shape were changed by a-SMA over production and F-actin over assembly due to a $\left[\mathrm{Ca}^{2+}\right]_{i}$ signal transduction disorder by ECM-integrin-cytoskeletal axis in age-related vascular dysfunctions and diseases (Zhu et al., 2012; Sehgel et al., 2013).

An increase in aortic stiffness is often observed in people with hypertension, obesity and diabetes. In these vascular dysfunctions and diseases, the over production of $\alpha$-SMA within VSMC is a decisive contributor to cause the increased aortic stiffness (Sehgel et al., 2013; Jia et al., 2015). Calcium channel blockers, such as benidipine and nifedipine, block $\mathrm{Ca}^{2+}$ influx flowing from the extracellular space through the specific ion channel to enter in the VSMC and reduce $\left[\mathrm{Ca}^{2+}\right]_{\mathrm{i}}$ for the treatment of hypertensive patients. $\left[\mathrm{Ca}^{2+}\right]_{i}$ declination can promote the reduction of $\alpha$-SMA expression and the breakdown of F-actin filaments in VSMCs, thereby reducing arterial stiffness and blood pressure (Miao et al., 2015; Yang et al., 2019). The drug thapsigargin inhibits the internal store (sarco/endoplasmic reticulum) $\mathrm{Ca}^{2+}$-ATPases to increase $\left[\mathrm{Ca}^{2+}\right]_{\mathrm{i}}$ and correspondingly enhances VSMC stiffness by developing the over expression of a-SMA (Cheng et al., 2019). These results indicated a high degree of correlation between the increase in $\left[\mathrm{Ca}^{2+}\right]_{i}$ and the a-SMA expression and VSMC stiffness.

\section{$\left[\mathrm{Ca}^{2+}\right]_{\mathrm{i}}$ Regulates $\alpha 5 \beta 1$ Integrin Activity in VSMCs}

Some observations supported a strong role for $\alpha 5 \beta 1$ integrin in increasing vascular tone and augmenting $\mathrm{Ca}^{2+}$ entry, whereas the role of $\operatorname{av} \beta 3$ integrin is present to reduce vascular tone and decrease $\mathrm{Ca}^{2+}$ entry. $\alpha 5 \beta 1$ integrin adheres to several major vascular ECM proteins, including fibronectin (FN), collagen I (COL-I), vitronectin (VN), and laminin I (LM), but the characteristics of adhesion to each protein are different with binding and signaling strongly associated with FN and COL-I (Sun et al., 2012; Hong et al., 2014, 2015). Previous application of blocking antibodies methods further identified that the interaction between $\mathrm{FN}$ and $\alpha 5 \beta 1$ integrin makes a specific and essential significance in the mechanical transduction of VSMC and confirmed $\alpha 5 \beta 1$ integrin to be the major receptor of FN (Sun et al., 2005, 2008; Wu et al., 2010). In integrin proteins, $\beta 1$ and $\beta 3$ subunits are responsible to perform a reverse function on $\mathrm{Ca}^{2+}$ entry. The mechanisms linking integrins to vascular control have not been entirely elucidated but some evidence showed that $\alpha 5 \beta 1$ and $\alpha v \beta 3$ integrins link to the regulation of $\mathrm{Ca}^{2+}$ entry through the L-type $\mathrm{Ca}^{2+}$ channel (Meininger and Davis, 1992; Wu et al., 1998, 2001). Most importantly, inhibition of a $5 \beta 1$ integrin will decrease $\mathrm{Ca}^{2+}$ signaling in response vasoconstrictors but $\mathrm{Ca}^{2+}$ signaling will be unaffected or enhanced by av $\beta 3$ inhibition (Janoštiak et al., 2014; Turner et al., 2015). The $\beta 1$ subunit protein enhances $\mathrm{Ca}^{2+}$ signaling to reflect VSMC elastic characterization, and inhibition of $\beta 1$ subunit will cause the declination of $\mathrm{Ca}^{2+}$ signaling for adhesion (Brozovich et al., 2016). Moreover, present researches verified that ionomycin increases $\left[\mathrm{Ca}^{2+}\right]_{i}$ level to enhance the a5 integrin subunit expression in VSMCs and promote the adhesion activities to FN matrix. In verse, BAPTA-AM reduces the a5 integrin subunit expression and prevents the adhesion activities to FN matrix due to the lower $\left[\mathrm{Ca}^{2+}\right]_{\mathrm{i}}$ level (Zhu et al., 2018a) (Figure 1B, Reprinted from Zhu et al., 2018b by published permission). These data show that the $\alpha 5 \beta 1$ integrin is mainly responsible to act the VSMC adhesion to FN matrix via the regulation of $\left[\mathrm{Ca}^{2+}\right]_{\mathrm{i}}$ level. These results showed a high degree of correlation between the increase in $\left[\mathrm{Ca}^{2+}\right]_{i}$ and the a5 31 integrin activity and adhesion to FN matrix.

The intracellular $\mathrm{Ca}^{2+}$ is a central role to regulate the elasticity and adhesion of VSMC by configuring contractile and cellular signaling through the ECM-integrin cytoskeletal axis. The $\alpha$-SMA of cytoskeleton is the major factor and responds mechanical forces through integrin-mediated cell-ECM interactions to mediate VSMC stiffness and adhesive processes, and its activity and expression are modulated by $\left[\mathrm{Ca}^{2+}\right]_{\mathrm{i}}$. $\left[\mathrm{Ca}^{2+}\right]_{\mathrm{i}}$ regulates $\alpha 5 \beta 1$ integrin activity and expression, and the $\beta 1$ integrin subunit is responsible for $\mathrm{Ca}^{2+}$ entry. These information are important advances for us to understand the VSMC stiffness and ECM adhesion coordination mechanisms (Figure 2A, redline).

\section{$\left[\mathrm{Ca}^{2+}\right]_{\mathrm{i}}$ Influences VSMC Stiffness and Adhesion}

$\mathrm{Ca}^{2+}$ influx flows from ion channel on the plasma membrane and the internal store (sarco/endoplasmic reticulum) to modulate a series of cellular events including VSMC elastic function via some enzymes' phosphorylation. In VSMCs, G-proteincoupled receptor (GPCR) activates phospholipase C (PLC) and cleaves phosphatidylinositol 4,5-bisphosphate $\left(\mathrm{PIP}_{2}\right)$ into diacylglycerol (DAG) and inositol trisphosphate $\left(\mathrm{IP}_{3}\right)$ to form and participate $\mathrm{Ca}^{2+}$ activity. The IP3 diffuses to the sarcoplasmic reticulum (SR) and binds with a receptor on SR membrane to open a ligand-gated $\mathrm{Ca}^{2+}$ channel and increase $\left[\mathrm{Ca}^{2+}\right]_{\mathrm{i}}$. The DAG activates protein kinase C (PKC). The PKC often directly regulates and controls the opening and closing of L-type $\mathrm{Ca}^{2+}$ 

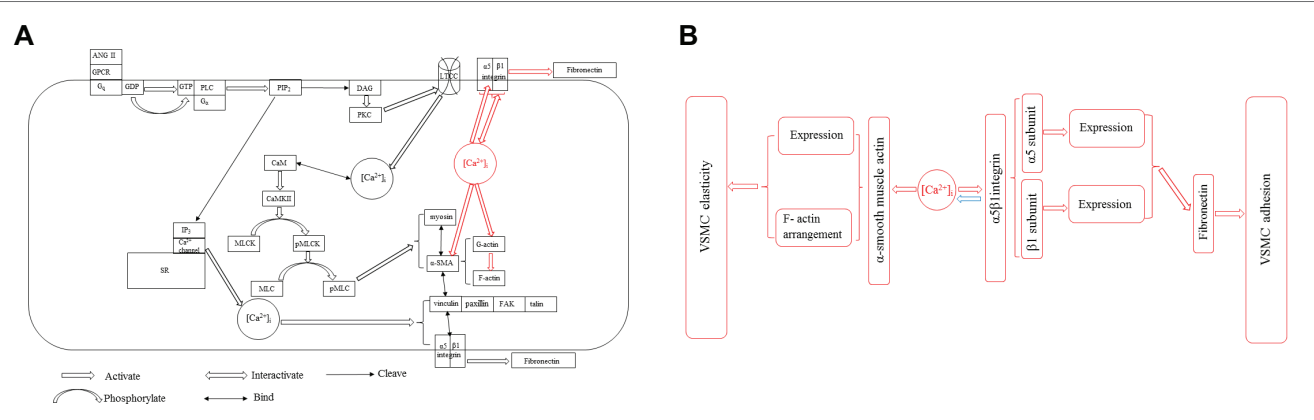

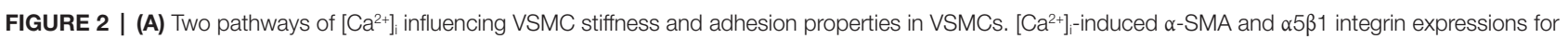
regulating VSMC stiffness and adhesion (red line) via ECM-integrin-cytoskeletal axis is parallel to the $\mathrm{Ca}^{2+}$-CaM-MLCK pathway in VSMCs (black line). All abbreviations in figure: $\left[\mathrm{Ca}^{2+}\right]_{\text {; }}$ Intercellular $\mathrm{Ca}^{2+}$ concentration; ANG II, Angiotensin II; GPCR, G-protein-coupled receptor; $\mathrm{G}_{\mathrm{q}}$, Guanine nucleotide-binding protein; GDP, Guanosine diphosphate; GTP, Guanosine triphosphate; $G_{\alpha}$, G protein a subunit; PLC, Phospholipase C; $\mathrm{PIP}_{2}$, Phosphatidylinositol 4,5-bisphosphate; IP, Inositol trisphosphate; DAG, Diacylglycerol; SR, Sarcoplasmic reticulum; PKC, Protein kinase C; LTCC, L-type Ca ${ }^{2+}$ channel; CaM, Calmodulin; CaMKII, CaMdependent protein kinase II; MLCK, Myosin light chain kinase; pMLCK, Phosphorylated myosin light chain kinase; MLC, Myosin light chain; pMLC, Myosin light chain phosphatase; $\alpha$-SMA, $\alpha$-smooth muscle actin; FAK, Focal adhesion kinase. (B) The new concept of $\left[\mathrm{Ca}^{2+}\right]$ i influencing VSMC stiffness and adhesion properties via ECM-integrin-cytoskeletal axis. [Ca $\left.{ }^{2+}\right]_{i}$ directly manipulates the expressions of $\alpha$-SMA and $\alpha 5 \beta 1$ integrin, and the $\alpha 5 \beta 1$ integrin regulates [Ca $\left.{ }^{2+}\right]_{i}$ level in accordance with physiological requirement.

channel (LTCC) by phosphorylation and dephosphorylation, while indirectly manipulates VSMC elastic and adhesive functions by triggering $\left[\mathrm{Ca}^{2+}\right]_{\mathrm{i}}$ level (Okuyama et al., 2018; Zhang et al., 2018). $\mathrm{Ca}^{2+}$ is the loop in excitation-contraction coupling. The LTCC is a voltage-gated calcium channel and responsible for excitation-contraction coupling in VSMCs. Calmodulin $(\mathrm{CaM})$ is a $\mathrm{Ca}^{2+}$-binding messenger protein to bind $\mathrm{Ca}^{2+}$ and transduce calcium signals performing its function. $\left[\mathrm{Ca}^{2+}\right]_{\mathrm{i}}$ binding with $\mathrm{CaM}$ activates $\mathrm{CaM}$-dependent protein kinase II (CaMKII) to regulate the activation of myosin light chain kinase (MLCK) by phosphorylation and controls the interaction between $\alpha$-SMA and myosin to affect the VSMC elasticity and adhesion process, while reducing the level of $\left[\mathrm{Ca}^{2+}\right]_{\mathrm{i}}$ by dephosphorylation inhibits the activity of MLCK to promote vascular smooth muscle relaxation (Snedden and Fromm, 2001; Martinsen et al., 2014). $\mathrm{Ca}^{2+}$ also retracts from cytoplasm to the internal store and extracellular space to decrease $\left[\mathrm{Ca}^{2+}\right]_{\mathrm{i}}$ level via the dephosphorylation of those enzymes, meanwhile inhibits myosin light chain phosphatase (pMLC) to hydrate the establishment with a-SMA (Kuo and Ehrlich, 2015; Saddouk et al., 2017). Many proteins involved in VSMC stiffness and adhesion including actin coordinating proteins are generated and driven by intracellular $\mathrm{Ca}^{2+}$, such as gelsolin, talin, vinculin, and cadherin (Martinez-Lemus et al., 2009; Hong et al., 2014). Gelsolin responds to the assembly and breakdown of actin filaments, and its activity is stimulated by $\left[\mathrm{Ca}^{2+}\right]_{\mathrm{i}}$ (Mikami et al., 2017). Cadherin responds VSMC adhesion and depends on $\left[\mathrm{Ca}^{2+}\right]_{\mathrm{i}}$ level (Desai et al., 2019). Vinculin is an actin binding protein and the bridge protein between talin and $\alpha$-SMA, which is a target protein of PKC phosphorylation driven by $\left[\mathrm{Ca}^{2+}\right]_{i}$ (Shen et al., 2019). Active intracellular $\mathrm{Ca}^{2+}$ induces to form the complex with FAK, talin, paxillin, and other components, and the complex enhances VSMC adhesion to FN matrix (Hong et al., 2015). The balance between phosphorylation and dephosphorylation for the activities of those enzymes is determined by the activity of intracellular $\mathrm{Ca}^{2+}$, and VSMCs are regulated by a complex network of phosphorylation and dephosphorylation kinase cascade from $\mathrm{Ca}^{2+}$ generation (Saddouk et al., 2017). Blebbistatin, which is a highly affinitive and selective inhibitor to myosin activity and phosphorylation, declines $\left[\mathrm{Ca}^{2+}\right]_{\mathrm{i}}$ activity for restraining vascular smooth muscle contraction to treat hypertension and some age-related vascular diseases (Zhang et al., 2017). The drug lysophosphatidic acid (LPA) enhances a $5 \beta 1$ integrin adhesion to FN matrix and activates Rho kinase to act as a signaling molecule and promote the level of $\left[\mathrm{Ca}^{2+}\right]_{\mathrm{i}}$ (Staiculescu et al., 2014), whereas the drug Y27632 inhibits the Rho-associated protein kinase (ROCK) to dephosphorylate and prevents a-SMA binding with myosin to decrease the need of $\left[\mathrm{Ca}^{2+}\right]_{\mathrm{i}}$ and attenuate the VSMC elasticity and adhesion (Zhou et al., 2017b). MLCK and pMLC were found to be over expressed in spontaneously hypertensive rats to stiffen the VSMC and attenuate the coordinate ability of ECM-integrinactin owing to the low activity and oscillation behavior of $\left[\mathrm{Ca}^{2+}\right]_{\mathrm{i}}$ (Sehgel et al., 2013; Rodenbeck et al., 2017). ML7 is a MLCK inhibitor to treat the VSMCs exploring the role of a $\left[\mathrm{Ca}^{2+}\right]_{\mathrm{i}}$ dependent actin-myosin interaction and cause an reduction of VSMC stiffness and adhesion decreasing $\left[\mathrm{Ca}^{2+}\right]_{\mathrm{i}}$ level of VSMC (Zhu et al., 2012; Cheng et al., 2015; Huang et al., 2018). $\mathrm{KCl}$ was acted as a non-receptor agonist to elevate $\left[\mathrm{Ca}^{2+}\right]_{\mathrm{i}}$ and treated VSMCs to show a rapid transient increase in cell stiffness as well as cell adhesion to FN matrix due to transiently increasing in the level of $\left[\mathrm{Ca}^{2+}\right]_{\mathrm{i}}$, after $\mathrm{KCl}$ treatment the increased VSMC stiffness and adhesion to FN matrix were not abolished by MLCK inhibitor (Huang et al., 2018). These observations suggest that $\mathrm{Ca}^{2+}$-CaM-MLCK pathway in VSMCs is parallel to $\left[\mathrm{Ca}^{2+}\right]_{\mathrm{i}}$-induced $\alpha$-SMA and $\alpha 5 \beta 1$ integrin expressions for regulating VSMC stiffness and adhesion (Figure 2A, blackline).

ATP-dependent $\mathrm{Ca}^{2+}$ pump and $\mathrm{Na}^{+} / \mathrm{Ca}^{2+}$ exchanger are two basic mechanisms for $\mathrm{Ca}^{2+}$ entry and exit from cells (Nance et al., 2015). These two mechanisms keep the balance of $\mathrm{Ca}^{2+}$ 
level between extracellular space and intracellular cytoplasm, and also keep the fluid and electrolyte balance of VSMCs to regulate cell normal physiological functions and elastic characters. The $\mathrm{Na}^{+} / \mathrm{Ca}^{2+}$ exchanger handles vascular tissues and blood pressure in human body through the regulation of VSMC elasticity (Ella et al., 2010). ATP-dependent $\mathrm{Ca}^{2+}$ pump and $\mathrm{Na}^{+} / \mathrm{Ca}^{2+}$ exchanger arise some damages of living organisms, and dehydration and overhydration will derive from the unbalances of electrolytes $\mathrm{Na}^{+}, \mathrm{Ca}^{2+}, \mathrm{K}^{+}, \mathrm{Cl}^{-}, \mathrm{HPO}_{3}^{2-}, \mathrm{H}_{2} \mathrm{PO}_{3}^{-}$, $\mathrm{PO}_{4}^{3-}$, and $\mathrm{Mg}^{2+}$ (Cheng et al., 2019). If fluid and electrolyte unbalances happen, living organisms will be edema in vascular tissues. VSMCs lose the elastic characterization and adhesive interaction between ECM and cytoskeleton, and the diameters of blood vessels will be diminished and the flow blood meets a strong and vehement stress from a narrow blood lumen. The fluid and electrolyte unbalances also possibly cause the deposits of salt minerals, and many salt minerals are inside VSMC and disturb a lot of cellular functions including cell elasticity and adhesion (Ngai et al., 2018; Tangvoraphonkchai and Davenport, 2018). Additionally, ATP-dependent $\mathrm{Ca}^{2+}$ pump and $\mathrm{Na}^{+} / \mathrm{Ca}^{2+}$ exchanger occur some pathological damages to produce a lot of crisis and hardness affecting the entry and release of $\mathrm{Ca}^{2+}$ and making $\left[\mathrm{Ca}^{2+}\right]_{\mathrm{i}}$ declination. This declination will reduce $\mathrm{Ca}^{2+}$ signaling function for that phosphorylation and dephosphorylation activate or deactivate the corresponding enzymes to generate a cascade cycle for the modulation of VSMC elastic and adhesive characterizations. The abnormal $\mathrm{Ca}^{2+}$ release and entry promote pathological reactions to induce calcification, and the main form of calcification is calcium phosphate crystalline in VMSCs. Meanwhile, the produced calcium salts harden to lose the corresponding physiological mediation functions (Sun et al., 2017). Phosphorylation and dephosphorylation are the balance to activate some enzymes modulating a cascade cycle for $\mathrm{Ca}^{2+}$ regulation, but calcification cuts off all pathways and makes $\mathrm{Ca}^{2+}$ to fully lose its activity, and further induces VSMCs to thoroughly lose elastic and adhesive functions (Ngai et al., 2018). The calcification of VSMC is a very strongly risk factor to cause blood circulation morbidity and vascular mortality, and the detailed biochemical and pathological mechanisms are currently unknown (Leopold, 2015; McArthur et al., 2017).

\section{REFERENCES}

Brozovich, F. V., Nicholson, C. J., Degen, C. V., Gao, Y. Z., Aggarwal, M., and Morgan, K. G. (2016). Mechanisms of vascular smooth muscle contraction and the basis for pharmacologic treatment of smooth muscle disorders. Pharmacol. Rev. 68, 476-532. doi: 10.1124/pr.115.010652

Cheng, X., Wang, X., Wan, Y., Zhou, Q., Zhu, H., and Wang, Y. (2015). Myosin light chain kinase inhibitor ML7 improves vascular endothelial dysfunction via tight junction regulation in a rabbit model of atherosclerosis. Mol. Med. Rep. 12, 4109-4116. doi: 10.3892/mmr.2015.3973

Cheng, J., Wen, J., Wang, N., Wang, C., Xu, Q., and Yang, Y. (2019). Ion channels and vascular diseases. Arterioscler. Thromb. Vasc. Biol. 39, e146-e156. doi: 10.1161/ATVBAHA.119.312004

Desai, A., Geraghty, S., and Dean, D. (2019). Effects of blocking integrin $\beta 1$ and N-cadherin cellular interactions on mechanical properties of vascular smooth muscle cells. J. Biomech. 82, 337-345. doi: 10.1016/j.jbiomech.2018.11.004

\section{CONCLUSION}

$\left[\mathrm{Ca}^{2+}\right]_{\mathrm{i}}$ directly manipulates the expressions of $\alpha$-SMA and $\alpha 5 \beta 1$ integrin, and the $\alpha 5 \beta 1$ integrin regulates $\left[\mathrm{Ca}^{2+}\right]_{\mathrm{i}}$ level in accordance with physiological requirement (Figure 2B). This investigation is parallel to the $\mathrm{Ca}^{2+}$-CaM-MLCK pathway to influence VSMC stiffness and adhesion via ECM-integrin-cytoskeletal axis without any cascade cycles by phosphorylation and dephosphorylation. However, the physiological mechanism need to be further probed. This investigation factually plays an independent pathway to regulate VSMC stiffness and adhesion via ECM-integrin-cytoskeletal axis and provides a new therapy approach to target $\alpha$-SMA or a5 $\beta 1$ integrin for influencing VSMC stiffness and adhesion and treat some vascular dysfunctions and diseases. Animal models provide important clues for exploring the pathogenesis of vascular dysfunctions and diseases to study how $\left[\mathrm{Ca}^{2+}\right]_{\mathrm{i}}$ to regulate and mediate VSMC elastic and adhesive functions in living organisms (Lacolley et al., 2014; Qiu et al., 2014). The performance at a single cell level is still a main research direction, and the observation will be focused on in vivo rather than in vitro because the normal physiological processes in living organisms provide some novel views to revolve $\left[\mathrm{Ca}^{2+}\right]_{\mathrm{i}}$ role in VSMC elastic and adhesive activities. In general, a more in-depth study of the $\left[\mathrm{Ca}^{2+}\right]_{\mathrm{i}}$ track and role in VSMC elastic and adhesive activities in vivo and in vitro for vascular physiological and pathological processes is the future extension and direction, and the significant advancements will contribute some novel clinic approaches to vascular disease.

\section{AUTHOR CONTRIBUTIONS}

YZhu drafted and designed manuscript. YZhu, JQ, LH, SY, and YZhou edited and revised manuscript. YZhu, FZ, and ZZ prepared figures. YZhu, JQ, LH, FZ, ZZ, SY, and YZhou approved final version of manuscript.

\section{FUNDING}

This review was supported by NIH grants HL124076, HL139584 and EY027924.

Dhar, S., Sun, Z., Meininger, G. A., and Hill, M. A. (2017). Nonenzymatic glycation interferes with fibronectin-integrin interactions in vascular smooth muscle cells. Microcirculation 24:e12347. doi: 10.1016/j.humimm.2019.06.001

DuPont, J. J., Kenney, R. M., Patel, A. R., and Jaffe, I. Z. (2019). Sex differences in mechanisms of arterial stiffness. Br. J. Pharmacol. 1-18. doi: 10.1111/ bph. 14624

Ella, S. R., Yang, Y., Clifford, P. S., Gulia, J., Dora, K. A., Meininger, G. A., et al. (2010). Development of an image-based system for measurement of membrane potential, intracellular $\mathrm{Ca}^{2+}$ and contraction in arteriolar smooth muscle cells. Microcirculation 17, 629-640. doi: 10.1111/j.1549-8719. 2010.00059.x

Ghosh, D., Syed, A. U., Prada, M. P., Nystoriak, M. A., Santana, L. F., NievesCintrón, M., et al. (2017). Calcium channels in vascular smooth muscle. Adv. Pharmacol. 78, 49-87. doi: 10.1016/bs.apha.2016.08.002

Hartman, C. D., Isenberg, B. C., Chua, S. G., and Wong, J. Y. (2016). Vascular smooth muscle cell durotaxis depends on extracellular matrix composition. Proc. Natl. Acad. Sci. USA 113, 11190-11195. doi: 10.1073/pnas.1611324113 
Hays, T. T., Ma, B., Zhou, N., Stoll, S., Pearce, W. J., and Qiu, H. (2018). Vascular smooth muscle cells direct extracellular dysregulation in aortic stiffening of hypertensive rats. Aging Cell 17:e12748. doi: 10.1111/ acel. 12748

Hill, M. A., and Meininger, G. A. (2016). Small artery mechanobiology: roles of cellular and non-cellular elements. Microcirculation 23, 611-613. doi: $10.1111 /$ micc. 12323

Hong, Z., Reeves, K. J., Sun, Z., Li, Z., Brown, N. J., and Meininger, G. A. (2015). Vascular smooth muscle cell stiffness and adhesion to collagen I modified by vasoactive agonists. PLoS One 10:e0119533. doi: 10.1371/journal.pone.0119533

Hong, Z., Sun, Z., Li, M., Li, Z., Bunyak, F., Ersoy, I., et al. (2014). Vasoactive agonists exert dynamic and coordinated effects on vascular smooth muscle cell elasticity, cytoskeletal remodelling and adhesion. J. Physiol. 592, 1249-1266. doi: 10.1113/jphysiol.2013.264929

Hong, Z., Sun, Z., Li, Z., Mesquitta, W. T., Trzeciakowski, J. P., and Meininger, G. A. (2012). Coordination of fibronectin adhesion with contraction and relaxation in microvascular smooth muscle. Cardiovasc. Res. 96, 73-80. doi: 10.1093/ cvr/cvs239

Huang, H., Sun, Z., Hill, M. A., and Meininger, G. A. (2018). A calcium medicated mechanism coordinating vascular smooth muscle cell adhesion during $\mathrm{KCl}$ activation. Front. Physiol. 9:a1810. doi: 10.3389/ fphys.2018.01810

Janoštiak, R., Pataki, A. C., Brábek, J., and Rösel, D. (2014). Mechanosensors in integrin signaling: the emerging role of p130Cas. Eur. J. Cell Biol. 93, 445-454. doi: 10.1016/j.ejcb.2014.07.002

Jia, G., Habibi, J., DeMarco, V. G., Martinez-Lemus, L. A., Ma, L., Whaley-Connell, A. T., et al. (2015). Endothelial mineralocorticoid receptor deletion prevents diet-induced cardiac diastolic dysfunction in females. Hypertension 66, 1159-1167. doi: 10.1161/ HYPERTENSIONAHA.115.06015

Khalili, A., and Ahmad, M. (2015). A review of cell adhesion studies for biomedical and biological applications. Int. J. Mol. Sci. 16, 18149-18184. doi: $10.3390 /$ ijms160818149

Kuo, I. Y., and Ehrlich, B. E. (2015). Signaling in muscle contraction. Cold Spring Harb. Perspect. Biol. 7:a006023. doi: 10.1101/cshperspect.a006023,

Lacolley, P., Regnault, V., and Avolio, A. P. (2018). Smooth muscle cell and arterial aging: basic and clinical aspects. Cardiovasc. Res. 114, 513-528. doi: $10.1093 /$ cvr/cvy009

Lacolley, P., Regnault, V., Segers, P., and Laurent, S. (2017). Vascular smooth muscle cells and arterial stiffening: relevance in development, aging, and disease. Physiol. Rev. 97, 1555-1617. doi: 10.1152/physrev.00003.2017

Lacolley, P., Thornton, S. N., and Bezie, Y. (2014). "Animal models for studies of arterial stiffness" in Blood pressure and arterial wall mechanics in cardiovascular diseases. ed. M. E. Safar (London: Springer), 63-74. doi: 10.1007/978-1-4471-5198-2

Laurent, S., and Boutouyrie, P. (2015). The structural factor of hypertension: large and small artery alterations. Circ. Res. 116, 1007-1021. doi: 10.1161/ CIRCRESAHA.116.303596

Leloup, A. J. A., Van Hove, C. E., De Moudt, S., De Meyer, G. R. Y., De Keulenaer, G. W., and Fransen, P. (2019). Vascular smooth muscle cell contraction and relaxation in the isolated aorta: a critical regulator of large artery compliance. Physiol. Rep. 7:e13934. doi: 10.14814/phy2.13934

Leopold, J. A. (2015). Vascular calcification: mechanisms of vascular smooth muscle cell calcification. Trends Cardiovasc. Med. 25, 267-274. doi: 10.1016/j. tcm.2014.10.021

Li, N., Sanyour, H., Remund, T., Kelly, P., and Hong, Z. (2018). Vascular extracellular matrix and fibroblasts-coculture directed differentiation of human mesenchymal stem cells toward smooth muscle-like cells for vascular tissue engineering. Mater. Sci. Eng. C 93, 61-69. doi: 10.1016/j.msec.2018.07.061

Martinez-Lemus, L. A., Hill, M. A., and Meininger, G. A. (2009). The plastic nature of the vascular wall: a continuum of remodeling events contributing to control of arteriolar diameter and structure. Physiology 24, 45-57. doi: 10.1152/physiol.00029.2008

Martinsen, A., Dessy, C., and Morel, N. (2014). Regulation of calcium channels in smooth muscle: new insights into the role of myosin light chain kinase. Channels 8, 402-413. doi: 10.4161/19336950.2014.950537

McArthur, K. M., Kay, A. M., Mosier, J. A., Grant, J. N., Stewart, J. A., and Simpson, C. L. (2017). Manipulating the plasticity of smooth muscle cells to regulate vascular calcification. AIMS Cell Tissue Eng. 1, 165-179. doi: 10.3934/celltissue.2017.3.165

Meininger, G. A., and Davis, M. J. (1992). Cellular mechanisms involved in the vascular myogenic response. Am. J. Phys. Heart Circ. Phys. 263, H647-H659. doi: 10.1152/ajpheart.1992.263.3.H647

Meininger, G. A., Zawieja, D. C., Falcone, J. C., Hill, M. A., and Davey, J. P. (1991). Calcium measurement in isolated arterioles during myogenic and agonist stimulation. Am. J. Physiol. Heart Circ. Physiol. 261, H950-H959. doi: 10.1152/ajpheart.1991.261.3.H950

Miao, X. N., Siu, K. L., and Cai, H. (2015). Nifedipine attenuation of abdominal aortic aneurysm in hypertensive and non-hypertensive mice: mechanisms and implications. J. Mol. Cell. Cardiol. 87, 152-159. doi: 10.1016/j.yjmcc.2015.07.031

Mikami, M., Zhang, Y., Danielsson, J., Joell, T., Yong, H. M., Townsend, E., et al. (2017). Impaired relaxation of airway smooth muscle in mice lacking the actin-binding protein gelsolin. Am. J. Respir. Cell Mol. Biol. 56, 628-636. doi: $10.1165 / \mathrm{rcmb} .2016-0292 \mathrm{OC}$

Nance, M. E., Whitfield, J. T., Zhu, Y., Gibson, A. K., Hanft, L. M., Campbell, K. S., et al. (2015). Attenuated sarcomere lengthening of the aged murine left ventricle observed using two-photon fluorescence microscopy. Am. J. Phys. Heart Circ. Phys. 309, H918-H925. doi: 10.1152/ajpheart.00315.2015

Ngai, D., Lino, M., and Bendeck, M. P. (2018). Cell-matrix interactions and matricrine signaling in the pathogenesis of vascular calcification. Front. Cardiovasc. Med. 5:a00174. doi: 10.3389/fcvm.2018.00174

Okuyama, Y., Hirawa, N., Fujita, M., Fujiwara, A., Ehara, Y., Yatsu, K., et al. (2018). The effects of anti-hypertensive drugs and the mechanism of hypertension in vascular smooth muscle cell-specific ATP2B1 knockout mice. Hypertens. Res. 41, 80-87. doi: 10.1038/hr.2017.92

Pierce, G. L. (2017). Mechanisms and subclinical consequences of aortic stiffness. Hypertension 70, 848-853. doi: 10.1161/HYPERTENSIONAHA.117.08933

Qiu, J., Zheng, Y., Hu, J., Liao, D., Gregersen, H., Deng, X., et al. (2014). Biomechanical regulation of vascular smooth muscle cell functions: from in vitro to in vivo understanding. J. Royal Soc. Interface 11:20130852. doi: 10.1098/rsif.2013.0852

Qiu, H., Zhu, Y., Sun, Z., Trzeciakowski, J. P., Gansner, M., Depre, C., et al. (2010). Short communication: vascular smooth muscle cell stiffness as a mechanism for increased aortic stiffness with aging. Circ. Res. 107, 615-619. doi: 10.1161/CIRCRESAHA.110.221846

Rodenbeck, S. D., Zarse, C. A., McKenney-Drake, M. L., Bruning, R. S., Sturek, M., Chen, N. X., et al. (2017). Intracellular calcium increases in vascular smooth muscle cells with progression of chronic kidney disease in a rat model. Nephrol. Dial. Transplant. 32, 450-458. doi: 10.1093/ndt/gfw274

Saddouk, F. Z., Ginnan, R., and Singer, H. A. (2017). Ca ${ }^{2+} /$ calmodulin-dependent protein kinase II in vascular smooth muscle. Adv. Pharmacol. 78, 171-202. doi: 10.1016/bs.apha.2016.08.003

Sanyour, H., Childs, J., Meininger, G. A., and Hong, Z. (2018). Spontaneous oscillation in cell adhesion and stiffness measured using atomic force microscopy. Sci. Report. 8:a2899. doi: 10.1038/s41598-018-21253-9

Sanyour, H. J., Li, N., Rickel, A. P., Childs, J. D., Kinser, C. N., and Hong, Z. K. (2019). Membrane cholesterol and substrate stiffness coordinate to induce the remodeling of the cytoskeleton and the alteration in the biomechanics of vascular smooth muscle cells. Cardiovasc. Res. 115, 1369-1380. doi: 10.1093/cvr/cvy276

Sehgel, N. L., Sun, Z., Hong, Z., Hunter, W. C., Hill, M. A., Vatner, D. E., et al. (2015a). Augmented vascular smooth muscle cell stiffness and adhesion when hypertension is superimposed on aging. Hypertension 65, 370-377. doi: 10.1161/HYPERTENSIONAHA.114.04456

Sehgel, N. L., Vatner, S. F., and Meininger, G. A. (2015b). "Smooth Muscle Cell Stiffness Syndrome"-Revisiting the structural basis of arterial stiffness. Front. Physiol. 6:a00335. doi: 10.3389/fphys.2015.00335

Sehgel, N. L., Zhu, Y., Sun, Z., Trzeciakowski, J. P., Hong, Z. K., Hunter, W. C., et al. (2013). Increased vascular smooth muscle cell stiffness: a novel mechanism for aortic stiffness in hypertension. Am. J. Physiol. Heart Circ. Physiol. 305, H1281-H1287. doi: 10.1152/ajpheart.00232.2013

Shen, K., Kenche, H., Zhao, H., Li, J., and Stone, J. (2019). The role of extracellular matrix stiffness in regulating cytoskeletal remodeling via vinculin in synthetic smooth muscle cells. Biochem. Biophys. Res. Commun. 508, 302-307. doi: 10.1016/j.bbrc.2018.11.142

Snedden, W. A., and Fromm, H. (2001). Calmodulin as a versatile calcium signal transducer in plants. New Phytol. 151, 35-66. doi: 10.1046/j.1469-8137. 2001.00154.x 
Staiculescu, M. C., Ramirez-Perez, F. I., Castorena-Gonzalez, J. A., Hong, Z., Sun, Z., Meininger, G. A., et al. (2014). Lysophosphatidic acid induces integrin activation in vascular smooth muscle and alters arteriolar myogenic vasoconstriction. Front. Physiol. 5:a00413. doi: 10.3389/fphys.2014.00413

Sun, Y., Byon, C. H., Yang, Y., Bradley, W. E., Dell'Italia, L. J., Sanders, P. W., et al. (2017). Dietary potassium regulates vascular calcification and arterial stiffness. JCI insight 2:e94920. doi: 10.1172/jci.insight.94920

Sun, Z., Li, Z., and Meininger, G. A. (2012). Mechanotransduction through fibronectin-integrin focal adhesion in microvascular smooth muscle cells: is calcium essential? Am. J. Physiol. Heart Circ. Physiol. 302, H1965-H1973. doi: 10.1152/ajpheart.00598.2011

Sun, Z., Martinez-Lemus, L. A., Hill, M. A., and Meininger, G. A. (2008). Extracellular matrix-specific focal adhesions in vascular smooth muscle produce mechanically active adhesion sites. Am. J. Phys. Cell Phys. 295, C268-C278. doi: 10.1152/ajpcell.00516.2007

Sun, Z., Martinez-Lemus, L. A., Trache, A., Trzeciakowski, J. P., Davis, G. E., Pohl, U., et al. (2005). Mechanical properties of the interaction between fibronectin and a5 $\beta 1$-integrin on vascular smooth muscle cells studied using atomic force microscopy. Am. J. Physiol. Heart Circ. Physiol. 289, H2526-H2535. doi: 10.1152/ajpheart.00658.2004

Tangvoraphonkchai, K., and Davenport, A. (2018). Magnesium and cardiovascular disease. Adv. Chronic Kidney Dis. 25, 251-260. doi: 10.1053/j.ackd.2018.02.010

Touyz, R. M., Alves-Lopes, R., Rios, F. J., Camargo, L. L., Anagnostopoulou, A., Arner, A., et al. (2018). Vascular smooth muscle contraction in hypertension. Cardiovasc. Res. 114, 529-539. doi: 10.1093/cvr/cvy023

Tsai, M.-S., Chiang, M.-T., Tsai, D.-L., Yang, C.-W., Hou, H.-S., Li, Y.-R., et al. (2018). Galectin-1 restricts vascular smooth muscle cell motility via modulating adhesion force and focal adhesion dynamics. Sci. Rep. 8:a11497. doi: 10.1038/ s41598-018-29843-3

Turner, C. J., Badu-Nkansah, K., Crowley, D., van der Flier, A., and Hynes, R. O. (2015). a5 and av integrins cooperate to regulate vascular smooth muscle and neural crest functions in vivo. Development 142, 797-808. doi: 10.1242/ dev. 117572

Wang, M., Kim, S. H., Monticone, R. E., and Lakatta, E. G. (2015). Matrix metalloproteinases promote arterial remodeling in aging, hypertension, and atherosclerosis. Hypertension 65, 698-703. doi: 10.1161/HYPERTENSIONAHA. 114.03618

Wu, X., Davis, G. E., Meininger, G. A., Wilson, E., and Davis, M. J. (2001). Regulation of the L-type calcium channel by $\alpha 5 \beta 1$ integrin requires signaling between focal adhesion proteins. J. Biol. Chem. 276, 30285-30292. doi: 10.1074/jbc.M102436200

Wu, X., Mogford, J. E., Platts, S. H., Davis, G. E., Meininger, G. A., and Davis, M. J. (1998). Modulation of calcium current in arteriolar smooth muscle by $\alpha v \beta 3$ and $\alpha 5 \beta 1$ integrin ligands. J. Cell Biol. 143, 241-252. doi: $10.1083 /$ jcb.143.1.241

Wu, X., Sun, Z., Foskett, A., Trzeciakowski, J. P., Meininger, G. A., and Muthuchamy, M. (2010). Cardiomyocyte contractile status is associated with differences in fibronectin and integrin interactions. Am. J. Physiol. Heart Circ. Physiol. 298, H2071-H2081. doi: 10.1152/ajpheart.01156.2009
Yang, Y., Chen, W., Wen, N., Cai, C., Liu, Q. H., and Shen, J. (2019). Benidipine, an anti-hypertensive drug, relaxes mouse airway smooth muscle. Life Sci. 227, 74-81. doi: 10.1016/j.lfs.2019.04.036

Yang, J., Jin, K., Xiao, J., Ma, J., and Ma, D. (2017). Endogenous tissue factor pathway inhibitor in vascular smooth muscle cells inhibits arterial thrombosis. Front. Med. 11, 403-409. doi: 10.1007/s11684-017-0522-y

Ye, G. J., Nesmith, A. P., and Parker, K. K. (2014). The role of mechanotransduction on vascular smooth muscle myocytes cytoskeleton and contractile function. Anat. Rec. 297, 1758-1769. doi: 10.1002/ar.22983

Zhang, Y., Li, L., Zhao, Y., Han, H., Hu, Y., Liang, D., et al. (2017). The myosin II inhibitor, blebbistatin, ameliorates $\mathrm{FeCl}_{3}$-induced arterial thrombosis via the GSK3ß-NF-кB pathway. Int. J. Biol. Sci. 13, 630-639. doi: 10.7150/ijbs.18485

Zhang, Z., Wen, Y., Du, J., Yu, Y., Liu, S., Wu, X., et al. (2018). Effects of mechanical stretch on the functions of $\mathrm{BK}$ and L-type $\mathrm{Ca}^{2+}$ channels in vascular smooth muscle cells. J. Biomech. 67, 18-23. doi: 10.1016/j. jbiomech.2017.11.015

Zhang, J., Zhao, X., Vatner, D. E., McNulty, T., Bishop, S., Sun, Z., et al. (2016). Extracellular matrix disarray as a mechanism for greater abdominal versus thoracic aortic stiffness with aging in primates. Arterioscler. Thromb. Vasc. Biol. 36, 700-706. doi: 10.1161/ATVBAHA.115.306563

Zhou, N., Lee, J.-J., Stoll, S., Ma, B., Costa, K. D., and Qiu, H. (2017b). Rho kinase regulates aortic vascular smooth muscle cell stiffness via actin/SRF/myocardin in hypertension. Cell. Physiol. Biochem. 44, 701-715. doi: 10.1159/000485284

Zhou, N., Lee, J. J., Stoll, S., Ma, B., Wiener, R., Wang, C., et al. (2017a). Inhibition of SRF/myocardin reduces aortic stiffness by targeting vascular smooth muscle cell stiffening in hypertension. Cardiovasc. Res. 113, 171-182. doi: $10.1093 / \mathrm{cvr} / \mathrm{cvw} 222$

Zhu, Y., He, L., Qu, J., and Zhou, Y. (2018a). Regulation of vascular smooth muscle cell stiffness and adhesion by $\left[\mathrm{Ca}^{2+}\right]_{\mathrm{i}}$ : an atomic force microscopybased study. Microsc. Microanal. 24, 708-712. doi: 10.1017/S1431927618015519

Zhu, W., Kim, B. C., Wang, M., Huang, J., Isak, A., Bexiga, N. M., et al. (2018b). TGF $\beta 1$ reinforces arterial aging in the vascular smooth muscle cell through a long-range regulation of the cytoskeletal stiffness. Sci. Rep. 8:a2668. doi: 10.1038/s41598-018-20763-w

Zhu, Y., Qiu, H., Trzeciakowski, J. P., Sun, Z., Li, Z., Hong, Z., et al. (2012). Temporal analysis of vascular smooth muscle cell elasticity and adhesion reveals oscillation waveforms that differ with aging. Aging Cell 11, 741-750. doi: $10.1111 / \mathrm{j} .1474-9726.2012 .00840 . \mathrm{x}$

Conflict of Interest Statement: The authors declare that the research was conducted in the absence of any commercial or financial relationships that could be construed as a potential conflict of interest.

Copyright (c) 2019 Zhu, Qu, He, Zhang, Zhou, Yang and Zhou. This is an open-access article distributed under the terms of the Creative Commons Attribution License (CC BY). The use, distribution or reproduction in other forums is permitted, provided the original author(s) and the copyright owner(s) are credited and that the original publication in this journal is cited, in accordance with accepted academic practice. No use, distribution or reproduction is permitted which does not comply with these terms. 